\title{
Clinical and Epidemiological Features of Psoriasis in Patients Visiting Lumbini Medical College
}

\author{
Jameel Akhtar Mikrani ${ }^{\mathrm{a}, \mathrm{c}}$, Arati Shrestha ${ }^{\mathrm{b}, \mathrm{c}}$.
}

\begin{abstract}
:
Background: Psoriasis is a worldwide disease and varies in its clinical profile and epidemiology in different regions of the world. The disease is common and few epidemiological data are available in our country. Objective: The purpose of this study was to evaluate the epidemiologic and clinical features of Psoriasis in Lumbini Medical College. Methods: A retrospective investigation of a total of 240 patients visiting Out Patient Department (OPD) of Dermatology and Venereology of Lumbini Medical College with Psoriasis was done. The parameters included were age at onset of disease, age at first treatment, current age, sex, type of disease and distribution of lesions. Data and statistical analysis was done with SPSS 17.0. Results: The mean age of patients at onset of disease was $26.4(S D=14.3)$ years. M:F ratio was 1.16. Psoriasis vulgaris (PV) was the most common variety of the disease. Extensor surface of the body was most commonly involved. Conclusion: Psoriasis is a common dermatological disease accounting $2.9 \%$ of all dermatology patients in our center. PV is the most common clinical subtype. The disease is more frequent in the third decade of life and has a male predominance in our region. Treatment compliance has been found to be poor.
\end{abstract}

Keywords: clinical $\bullet$ dermatologic $・$ epidemiology $\bullet$ psoriasis

\section{INTRODUCTION:}

Psoriasis is a common, chronic, disfiguring, inflammatory and proliferative condition of the skin, in which both genetic and environmental influences have a critical role. It is an autoimmune epidermal proliferative disease of the skin and connective tissue. Etiologic factors include environmental, genetic and immunologic factors. The most characteristic lesions consist of red, scaly, sharply demarcated, indurated plaques, present particularly over extensor surfaces and scalp (Fig 1). Morphological variants are common. The disease is enormously variable in duration, periodicity of flares and extent. ${ }^{1}$

a - Lecturer, Department of Dermatology and Venereology

b - Medical Officer

c - Lumbini Medical College, Palpa

Corresponding Author:

Dr. Jameel Akhtar Mikrani

e-mail: drjameelmikrani@gmail.com

How to cite this article:

Mikrani JA, Shrestha A. Clinical and Epidemiological features of Psoriasis in patients visiting Lumbini Medical College. Journal of Lumbini Medical College. 2014;2(1):1-3. doi: 10.22502/jlmc. v2i1.45.
There is considerable difference in the incidence of disease due to environmental, genetic and geographical factors. Prevalence in U.K. is $2.2 \%,{ }^{2} 8.5 \%$ in Norway, ${ }^{3} 5.2 \%$ in France, ${ }^{4} 6.6 \%$ in Australia, ${ }^{5} 2.2 \%$ in US, ${ }^{6} 2.3 \%$ in India, ${ }^{7} 0.4 \%$ in Sri Lanka, ${ }^{8} 0.3 \%$ in China. ${ }^{9}$

Psoriasis is a chronic disease that has a fluctuating course and the course is altered by the treatment. Psoriasis rarely causes mortality, but significantly affects the quality of life of the patient. In addition, it adds to the cost of treatment of the disease itself and its systemic involvement or

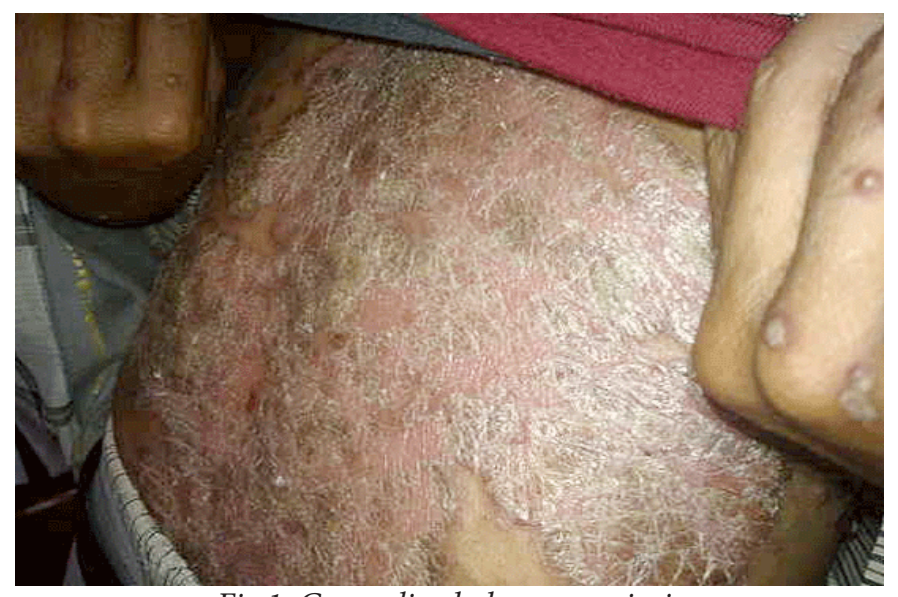

Fig 1: Generalized plaque psoriasis 
comorbidity. These patients have skin symptoms, may develop arthritis, depression and cardiovascular diseases. They may have obesity, hypertension and diabetes as comorbid conditions. As many as $15.5 \%$ of psoriasis patient develop psoriatic arthritis. ${ }^{2,4,5}$

There are many treatment options for this disease namely topical, systemic, phototherapy and biological agents. The outcome of the treatment may differ in different individuals. One should understand that the treatment is a control rather than cure. ${ }^{3-6}$

The current study presents the clinical and epidemiological features of psoriatic patients attending the dermatology Outpatient department of Lumbini Medical College Teaching Hospital, which is a 700 bedded multi-specialty hospital in the semiurban area of Lumbini, Nepal.

\section{METHODS:}

All patients diagnosed with Psoriasis from the Out-Patient Department of Dermatology and Venereology of Lumbini Medical College were selected for the study. Their records were reviewed retrospectively. Patients visiting from $1^{\text {st }}$ of June 2010 to $31^{\text {st }}$ of May 2013 were included in the study.

Sociodemographic data and subtype of disease was studied. All the data was entered into Microsoft Excel and statistical analyses were performed with SPSS 17. The descriptive statistics like percentage, proportion, mean and standard deviation was calculated. Statistical significance was analyzed at $p<0.05$.

\section{RESULTS:}

A total of 240 patients were enrolled in the study. Out of those, $129(53.75 \%)$ were male and $111(46.25 \%)$ were female. The patients' age ranged from 6 years to 86 years $(M=36.1, S D=22.3)$. The prevalence rate of this disease among Dermatology patients of LMC was 2.9\% (Male 2.5\% and Female $3.6 \%$ ). Mean age at onset was $26.4 \pm 14.3$ years $(29.7 \pm 13.8$ in male and $21.4 \pm 13.1$ in female). Mean age at first presentation to the hospital was $28.9 \pm 14.8$ years. The difference in the mean age at onset of disease and that at first hospital visit was statistically significant $(p<0.05)$. Most of the patients were getting treatment from various small clinics on irregular basis.

Patients of nine districts $(75$ districts in the Country) visited our hospital, namely Palpa, Syangja, Gulmi, Arghakhanchi, Baglung,
Table 1: Types of Psoriasis $(N=240)$

\begin{tabular}{lcc}
\hline Disease & $\boldsymbol{n}$ & $\boldsymbol{\%}$ \\
\hline Psoriasis Vulgaris & 192 & 80 \\
Psoriasis Guttate & 38 & 15.83 \\
Pustular Psoriasis & 5 & 2.08 \\
Psoriasis Palmo Plantar & 4 & 1.67 \\
Psoriasis Erythroderma & 1 & 0.42 \\
Others & 0 & 0 \\
\hline
\end{tabular}

Rupandehi, Kapilbastu, Nawalparasi and Parbat. Most patients (40.2\%) visited from Palpa where the Medical College is located.

Disease was classified as shown in Table 1. Psoriasis vulgaris was the most common type of disease which accounted for $80 \%$ of the cases. The most common site was extensor surfaces $(85.3 \%)$, scalp (46.6\%), hands and feet $(28.1 \%)$, lumbosacral region $(13.8 \%)$ and genitals $(3.2 \%)$.

\section{DISCUSSION:}

There are few clinical and epidemiological studies on psoriasis in our country. In our study $2.9 \%$ of the patients coming to dermatology department were suffering from Psoriasis. We do not have a national data on this condition but we assume this study to reflect the scenario of the country since most of the patients were from their permanent address. A similar study in the capital city showed the prevalence rate of $3.6 \% .^{10}$

Psoriasis was found to be more common in male $(53.75 \%)$ in our study with $\mathrm{M}: \mathrm{F}=1.16$. This finding is supported by various other studies. ${ }^{10-12}$ Some studies show that this disease is equal or more common in female. ${ }^{13}$ This may be a likely scenario even in our place due to limited access to health care facilities in case of female.

Psoriasis vulgaris was the most common variety in our study compromising $80 \%$ of the total cases. This result was supported by other studies. ${ }^{10,13}$ Extensors of the body, scalp, hands and feet were among the mostly affected body parts by the disease. These were some of the hallmark features of this disease.

\section{CONCLUSION:}

Psoriasis is a relatively common dermatological disease. It has affected $2.9 \%$ of the people visiting OPD of Dermatology and Venereology Department. It affects male more 
Mikrani JA. et al. Clinical and Epidemiological features of Psoriasis in patients visiting Lumbini Medical College.

than female. People are affected most in their third decade; however people coming to our center were mostly of fourth decade. Psoriasis vulgaris is the most common clinical type, accounting for $80 \%$ of the patients. Extensor surface of the body was the most affected region. Most of the patient had a poor compliance to treatment.

\section{REFERENCES:}

1. O'Daly JA. Psoriasis, a Systemic Disease Beyond the Skin, as Evidenced by Psoriatic Arthritis and Many Comorbidities Clinical Remission with a Leishmania Amastigotes Vaccine, a Serendipity Finding. In: O'Daly JA (ed.) Psoriasis- A Systemic Disease. USA: InTech; 2012:1-56. doi:10.5772/25789.

2. Seminara NM, Abuabara K, Shin DB, Langan SM, Kimmel SE, Margolis D. et al. Validity of The Health Improvement Network (THIN) for the study of psoriasis. Br J Dermatol. 2011 Mar;164(3):602-9.

3. Bo K, Thoresen M, Dalgard F. Smokers report more psoriasis, but not atopic dermatitis or hand eczema: results from a Norwegian population survey among adults. Dermatology. 2008;216(1):40-5.

4. Wolkenstein P, Revuz J, Roujeau JC, Bonnelye G, Grob JJ, Bastuji-Garin S et al. Psoriasis in France and associated risk factors: results of a case-control study based on a large community survey. Dermatology. 2009;218(2):103-9.

5. Kilkenny M, Stalhakis V, Jolley D, Marks R. Maryborough skin health survey: prevalence and sources of advice for skin conditions. Australas J Dermatol. 1998 Nov; 39(4):233-7.

6. Stern RS, Nijsten T, Feldman SR, Margolis DJ, Rolstad T. Psoriasis is common, carries a substantial burden even when not extensive, and is associated with widespread treatment dissatisfaction. J Investig Dermatol Symp Proc. 2004 Mar;9(2):136-9.

7. Gunawardena DA, Gunawardena KA, Vasanthanathan NS, Gunawardena JA. Psoriasis in Sri-Lanka - a computer analysis of 1366 cases. Br J Dermatol. 1978 Jan;98(1):85-96.

8. Yip SY. The prevalence of psoriasis in the Mongoloid race. J Am Acad Dermatol. 1984 Jun;10(6):965-8.

9. Shrestha DP, Gurung D. Psoriasis: Clinical and Epidemiological Features in a Hospital Based Study. Nepal Journal of Dermatology, Venerology \& Leprology. 2012;10(1):41-45.

10. Icen M, Crowson CS, McEvoy MT, Dann FJ, Gabriel SE, Maradit Kremers H. Trends in incidence of adult onset psoriasis over three decades: a population-based study. J Am Acad Dermatol. 2009 Mar;60(3):394-401.

11. Vena GA, Altomare G, Ayala F, Berardesca E, CalzavaraPinton $\mathrm{P}$, Chimenti S et al. Incidence of psoriasis and association with comorbidities in Italy: a 5-year observational study from a national primary care database. Eur J Dermatol. 2010 SepOct;20(5):593-8.

12. Menter A, Gottlieb A, Feldman SR, Van AS, Leonardi CL, Gordon $\mathrm{KB}$ et al. Guidelines of care for the management of psoriasis and psoriatic arthritis. J Am Acad Dermatol. 2008 May;58(5):826-50.

13. Cakmur H, Dervis E. The relationship between quality of life and the severity of psoriasis in Turkey. Eur J Dermatol. 2015;25(2):169-76. 